\title{
Efektivitas langkah-langkah peregangan (stretching) untuk menurunkan nyeri dismenore di wilayah Sleman Yogyakarta
}

\author{
Sherkia Ichtiarsi Prakasiwi* \\ Program Studi S1 Kebidanan, Universitas Muhammadiyah Semarang - Indonesia
}

\begin{abstract}
Dysmenorrhea is an imbalance of the hormone progesterone in the blood, causing pain to arise. Women have experienced $90 \%$ of dysmenorrhea, this disturbs $50 \%$ of women of reproductive age and $60-85 \%$ in adolescence, which results in many absences in schools and offices. Non-pharmacological solutions are seen as safer, one of which is stretching which aims to make muscles and joints flexible and elastic. This is due to increased levels of endorphins, epinephrine, dopamine and serotonin produced by the brain due to exercise. This study aims to determine stretching steps to reduce dysmenorrhea pain in the Sleman region. The method of this research is a different test study with a cross sectional type of research. The research sample was 60 female students. The sampling technique was purposive sampling, bivariate analysis techniques using the Mann Whitney statistical test using SPSS software. The results of the Mann Whitney test in the control group and the intervention group showed a p-value of $0,000(a<0.05)$ indicating that there were differences between the control and intervention groups in decreasing the level of pain in dysmenorrhea where the mean pain level of dysmenorrhea was 450 while in the intervention group the average is only 0.13 so that it gets $\Delta$ mean of -4.37 . This proves that stretching is more influential in decreasing the level of pain in dysmenorrhea than in stretching.
\end{abstract}

Keywords: stretching; pain in dysmenorrhea

\begin{abstract}
Dismenore merupakan ketidakseimbangan hormon progesteron dalam darah sehingga mengakibatkan rasa nyeri timbul. Wanita pernah mengalami dismenore sebanyak $90 \%$, ini mengganggu $50 \%$ wanita masa reproduksi dan $60-85 \%$ pada usia remaja, yang mengakibatkan banyaknya absensi pada sekolah maupun kantor. Solusi non farmakologis dipandang lebih aman, salah satunya adalah peregangan yang bertujuan untuk membuat otot dan persendian menjadi fleksibel dan elastis. Hal ini disebabkan karena meningkatnya kadar endorphin, epinephrine, dopamine dan serotonin yang dihasilkan oleh otak akibat olahraga. Penelitian ini bertujuan untuk mengetahui langkah-langkah peregangan (stretching) untuk menurunkan nyeri dismenore di wilayah Sleman. Metode penelitian ini adalah uji beda dengan jenis penelitian cross sectional. Sampel penelitian adalah santri putri berjumlah 60 responden. Teknik pengambilan sampel yaitu purposive sampling, teknik analisis bivariat menggunakan uji statistik Mann Whitney dengan menggunakan uji statistik. Hasil uji Mann Whitney pada kelompok kontrol dan kelompok intervensi didapatkan $\mathrm{p}$-value sebesar 0,000 $(\mathrm{a}<0,05)$ menunjukkan bahwa terdapat perbedaan antara kelompok kontrol dan intervensi terhadap penurunan tingkat nyeri dismenore dimana rata-rata tingkat nyeri dismenore pada kelompok kontrol sebesar 4,50 sedangkan pada kelompok intervensi rata ratanya hanya sebanyak 0,13 sehingga didapatkan $\Delta$ mean sebesar $-4,37$. Hal ini membuktikan bahwa pemberian peregangan (stretching) lebih berpengaruh terhadap penurunan tingkat nyeri dismenore dibandingkan yang tidak dilakukan peregangan (stretching).
\end{abstract}

Kata Kunci: peregangan; nyeri dismenore

"Korespondensi Penulis: Sherkia Ichtiarsi Prakasiwi (email: sherkia@unimus.ac.id.), Jl. Kedungmundu No.18, Kedungmundu, Kec. Tembalang, Kota Semarang, Jawa Tengah 50273. 


\section{Pendahuluan}

Dismenore diklasifikasikan menjadi dua, yaitu dismenore primer dan dismenore sekunder (Frech 2005; Osayande and Mehulic 2014; Potter and Perry 2010). Dismenore yang banyak terjadi adalah dismenore primer yaitu sebanyak $54,89 \%$, sedangkan dismenore sekunder hanya 9,36\%. Di Amerika Serikat, Klein dan Litt melaporkan prevalensi dismenore $59,7 \%$, yang mengeluh nyeri berat $12 \%$, nyeri sedang $37 \%$, dan nyeri ringan 49\% (Anurogo 2011). Prevalensi dismenore primer di Indonesia cukup tinggi yaitu $60-70 \%$ dan $15 \%$ diantaranya mengalami nyeri hebat yang umumnya terjadi pada usia remaja. Dismenore terjadi pada remaja dengan prevalensi berkisar antara $43 \%$ hingga 93\%, dimana sekitar $74-80 \%$ remaja mengalami dismenore ringan (Hestiantoro 2012).

Banyak cara mengatasi dismenore yaitu dengan cara farmakologis maupun non farmakologis. Solusi non farmakologis dipandang lebih aman karena tidak menimbulkan efek samping seperti obat-obatan (Ningsih, Setyowati, and Rahmah 2013). Terapi farmakologi pemberian obat-obatan analgetik, terapi hormonal, obat nonsteroid prostaglandin, dan dilatasi kanalis sevikalis, sedangkan terapi non farmakologi adalah kompres hangat, terapi relaksasi dengan mendengarkan musik, akupuntur, akupresure, exercise, dan terapi spiritual (Anurogo 2011). Olahraga (exercise) menghasilkan endorfin yang dihasilkan di otak dan sumsum tulang belakang. Hormon endorfin berfungsi sebagai obat penenang alami sehingga menimbulkan rasa nyaman (Anurogo 2011).
Peregangan (stretching) adalah bentuk dari penguluran atau peregangan (stretching) pada otot-otot di setiap anggota badan agar dalam setiap melakukan olahraga bertujuan untuk membuat otot dan persendian menjadi fleksibel dan elastis (S. Saleh, E. Mowafy, and El-Hameid 2016). Hal ini disebabkan karena meningkatnya kadar endorphin yang dihasilkan oleh otak akibat olahraga. Sehingga latihan fisik ini bertindak sebagai analgesik spesifik untuk jangka pendek dapat menghilangkan rasa sakit. Melakukan exercise tubuh akan menghasilkan endorphin, endorphin dihasilkan diotak dan susunan syaraf tulang belakang, berfungsi sebagai obat penenang alami, sehingga menimbulkan rasa nyaman, olahraga dapat meningkatkan kadar endorphin empat sampai lima kali didalam darah dan dapat mengurangi rasa nyeri pada saat kontraksi (Bahri, Afriwardi, and Yusrawati 2015; Harry 2007; Khairunnisa and Maulina 2018; Monica and Nasution 2017). Ketika seseorang melakukan exercise, maka endorphin akan keluar dan ditangkap oleh reseptor di dalam hipothalamus dan sistem limbik yang berfungsi untuk mengatur emosi dan mengurangi rasa nyeri, maka peregangan (stretching) dapat menurunkan rasa nyeri akibat dismenore.

\section{Metode Penelitian}

Penelitian yang digunakan adalah penelitian diuji beda dengan jenis penelitian cross sectional. Sampel penelitian adalah santri putri berjumlah 60 responden. Teknik pengambilan sampel yaitu purposive sampling, teknik analisis bivariat menggunakan uji statistik Mann Whitney dengan menggunakan software SPSS. Hasil uji 
Mann Whitney pada kelompok kontrol dan kelompok intervensi didapatkan $\mathrm{p}$-value sebesar $0,000(a<0,05)$.

\section{Hasil dan Pembahasan}

1. Perbedaan nyeri dismenore sebelum pretest dan sesudah post test pada kelompok intervensi menggunakan uji Wilcoxon. Lihat Tabel 1.

Berdasarkan tabel 1 nilai $p$ value $=0,00<a$ $(0,05)$. Maka dapat disimpulkan terdapat perbedaan nyeri dismenore sebelum dan setelah pada kelompok intervensi dimana nilai rata-rata sebelum diberikan peregangan (stretching) rata ratanya $5,13 \pm 3,99$ dan setelah diberikan peregangan (stretching) rata rata nyerinya turun menjadi $0,13 \pm 1,60$.

2. Perbedaan nyeri dismenore sebelum pretest dan sesudah post test pada kelompok kontrol. Lihat Tabel 2.

Berdasarkan tabel 2 nilai $p$ value $=0,083>a$ $(0,05)$. Maka dapat disimpulkan tidak terdapat perbedaan tingkat nyeri disminorrhea sebelum dan setelah pada kelompok kontrol. Dimana nilai rata-rata sebelum diberikan 4,60 $\pm 1,54$ dan setelah menjadi 4,53 $\pm 1,52$. Hasil dari perbedaan perubahan skor nyeri antara kelompok intervensi dan kelompok kontrol dapat di lihat melalui grafik pada Gambar 1.

Tabel 1. Perbedaan Nyeri Dismenore pada Kelompok Intervensi

\begin{tabular}{lccc}
\hline Variabel & $\mathrm{n}$ & Mean \pm SD & $p$ value \\
\hline Sebelum & 30 & $5,13 \pm 3,99$ & 0,000 \\
Sesudah & 30 & $0,13 \pm 1,60$ & \\
\hline
\end{tabular}

Tabel 2. Perbedaan Nyeri Dismenore pada Kelompok Kontrol

\begin{tabular}{lccc}
\hline Variabel & $\mathrm{n}$ & Mean \pm SD & p value \\
\hline Sebelum & 30 & $4,60 \pm 1,54$ & \multirow{2}{*}{0,080} \\
Sesudah & 30 & $4,53 \pm 1,52$ & \\
\hline
\end{tabular}

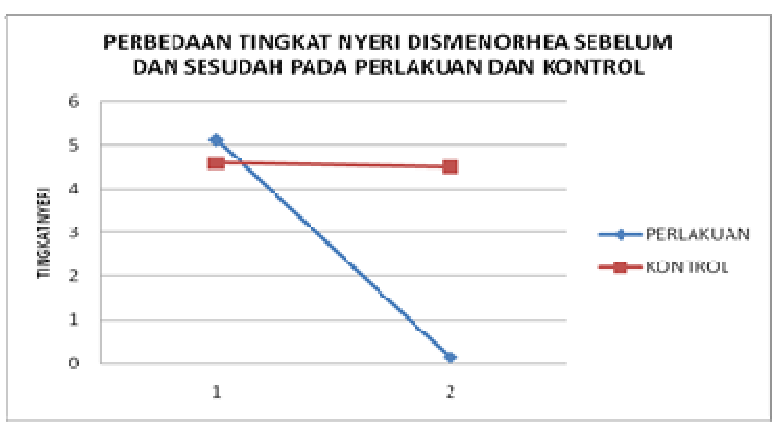

Gambar 1. Grafik Perbedaan Penurunan Nyeri Dismenore sebelum dan sesudah Pada Kelompok Intervensi dan Kelompok Kontrol 
3. Perbedaan Pengaruh Peregangan (stretching) terhadap nyeri dismenor. Data disajikan dengan menggunakan Mann Whitney pada Tabel 3.

Berdasarkan hasil uji Mann Whitney pada tabel 3 pada kelompok kontrol dan kelompok intervensi didapatkan $p$-value sebesar 0,000 ( $a<$ $0,05)$ menunjukkan bahwa terdapat perbedaan antara kelompok kontrol dan intervensi terhadap penurunan tingkat nyeri dismenore dimana rata-rata tingkat nyeri dismenore pada kelompok kontrol sebesar 4,50 sedangkan pada kelompok intervensi rata ratanya hanya sebanyak 0,13 sehingga didapatkan $\Delta$ mean sebesar -4,4. Hal ini membuktikan bahwa pemberian peregangan (stretching) lebih berpengaruh terhadap penurunan tingkat nyeri dismenore dibandingkan yang tidak dilakukan peregangan (stretching).

Peregangan (stretching) merupakan salah satu cara menurunkan nyeri non farmakologis. Peregangan (stretching) adalah bentuk dari penguluran atau peregangan (stretching) pada otot-otot di setiap anggota badan yang bertujuan membuat otot dan persendian menjadi fleksibel dan elastis. Hal ini disebabkan karena meningkatnya kadar endorphin yang dihasilkan oleh otak akibat olahraga. Sehingga latihan fisik ini bertindak sebagai analgesik spesifik untuk jangka pendek dapat menghilangkan rasa sakit. Melakukan exercise tubuh akan menghasilkan endorphin, endorphin dihasilkan diotak dan susunan syaraf tulang belakang, berfungsi sebagai obat penenang alami, sehingga menimbulkan rasa nyaman, olahraga dapat meningkatkan kadar endorphin empat sampai lima kali di dalam darah dan dapat mengurangi rasa nyeri pada saat kontraksi (Monica \& Nasution, 2017).

\section{Kesimpulan}

Hasil uji Mann Whitney pada kelompok kontrol dan kelompok intervensi didapatkan $\mathrm{p}$ value sebesar 0,000 ( $a<0,05)$ menunjukkan bahwa terdapat perbedaan antara kelompok kontrol dan intervensi terhadap penurunan tingkat nyeri dismenore dimana rata-rata tingkat nyeri dismenore pada kelompok kontrol sebesar 4,50 sedangkan pada kelompok intervensi rata ratanya hanya sebanyak 0,13 sehingga didapatkan mean sebesar -4,4. Hal ini membuktikan bahwa pemberian peregangan (stretching) lebih berpengaruh terhadap penurunan tingkat nyeri dismenore dibandingkan yang tidak dilakukan peregangan (stretching). []

Tabel 3. Perbandingan Selisih Nyeri Dismenore setelah Intervensi pada Kelompok Kontrol dan Kelompok Intervensi

\begin{tabular}{lccccc}
\hline \multirow{2}{*}{ Kelompok } & \multicolumn{2}{c}{ Setelah Intervensi } & $\Delta$ Mean & Mean & $p-$ \\
& Mean & SD & & Rank & value \\
\hline Kontrol & 4,53 & 1,60 & $-4,4$ & 45,32 & \multirow{2}{*}{0,000} \\
Intervensi & 0,13 & 0,57 & & 15,68 & \\
\hline
\end{tabular}




\section{Daftar Pustaka}

Anurogo, Anurogo. 2011. Cara jitu mengatasi nyeri haid. Yogjakarta: Andi Publisher.

Bahri, Ayu Anissa, A. Afriwardi, and Y. Yusrawati. 2015. "Hubungan antara kebiasaan olahraga dengan dismenore pada mahasiswi preklinik Program Studi Pendidikan Dokter Fakultas Kedokteran Universitas Andalas Tahun Ajaran 2012-2013." Jurnal Kesehatan Andalas 4(3):815-21.

Frech, Linda. 2005. "Dysmenorrhea." American Family Physician, January, 285-91.

Harry. 2007. "Mekanisme endorphin dalam tubuh."

Hestiantoro, Andon. 2012. Best Practices on imperial infertility, menopause, pcos, endometriosis, recurrent miscarriage, invitro fertilization, adolescent gynecology, abnormal uterine bleeding. Jakarta: Sagung Seto.

Khairunnisa and Nora Maulina. 2018. “Hubungan aktivitas fisik dengan nyeri haid (dismenorea) pada santriwati Madrasah Aliyah Swasta Ulumuddin Uteunkot Conda Kota Lhokseumawe." Averrous 3(1):10-20.
Monica, Ricca and Nursiah Nasution. 2017. "Pengaruh latihan fisik intensitas ringan dan sedang terhadap perubahan kadar hormon Beta - Endorphin Mencit (Mus Musculus L .) Hamil." Biomedical Journal of Indonesia 3(2):91-98.

Ningsih, Ratna, Setyowati Setyowati, and Hayuni Rahmah. 2013. "Efektivitas paket pereda nyeri pada remaja dengan dismenore." Jurnal Keperawatan Indonesia 16(2):67-76.

Osayande, Amimi S. and Suarna Mehulic. 2014. "Diagnosis and initial management of dysmenorrhea." American Family Physician, March, 341-346.

Potter, Patricia and Anne Perry. 2010. Fundamental keperawatan (3-Vol Set). 7th ed. Jakarta: Salemba Medika.

S. Saleh, Hend, Hala E. Mowafy, and Azza A. Abd ElHameid. 2016. "Stretching or Core strengthening exercises for managing primary dysmenorrhea." Journal of Womens Health Care 5(1):1-6. 
This page is intentionally left blank 